ARTIGO

Recebido em:

15/09/2015

Aceito em:

$02 / 12 / 2015$

\title{
Perspectivas e Desafios na Transparência das Contas Públicas: um estudo numa Instituição de Ensino Superior brasileira
}

Prospects and Challenges in Transparency of Public Accounts: a study in a Brazilian higher education institution

Janyluce Rezende GAMA

Doutoranda em Ciência da Informação (UnB) - janylucegama@gmail.com

Georgete Medleg RODRIGUES

Professora da Faculdade de Ciência da Informação (UnB) - medleg.georgete@gmail.com

\section{Resumo}

Este artigo visa analisar o processo de implementação da lei de acesso à informação (LAI) numa universidade federal brasileira e identificar as perspectivas e desafios dos gestores públicos em relação a esta legislação. Para isto, utilizou como metodologia uma abordagem qualitativa, que envolve a pesquisa de campo com a coleta de dados realizada por meio da aplicação de questionários. Os resultados mostram que no processo de implementação da LAI foi realizado um plano de ações, porém, este não foi implementado, pois o governo federal disponibilizou um sistema de uso obrigatório para todos os órgãos do executivo federal. Em relação às perspectivas dos gestores, o item que parece ter mais chances de se realizar foi "mais transparência nas contas de contratos, balanços, relatórios de auditoria, etc." Sobre os desafios, o item que mais se ressaltou foi "a falta de infraestrutura dos sistemas de informação e demais tecnologias". Conclui-se que faltam ações de apoio do governo federal para a efetiva implementação da LAI.

Palavras-chave: Lei de Acesso à Informação. Transparência. Contas Públicas. Universidades Públicas Federais.

Abstract

This paper aims to analyze the process of implementing the access to information law (LAI) in a Brazilian federal university and identify the prospects and challenges of public officials in relation to this legislation. For this, we used as a qualitative methodology approach, which involves field research with data collection conducted through questionnaires. The results show that the LAI implementation process was carried out an action plan, however, this was not implemented because the federal government released a mandatory use system for all agencies of the federal executive. About the prospects of managers, the item that seems to have more chances to perform was "more transparency in contracts accounts, balance sheets, audit reports, etc." On the challenges, the item that most said was "the lack of infrastructure of information systems and other technologies." It is concluded that lack support from the federal government actions for the effective implementation of LAI.

Keywords: Access to Information Act. Transparency. Public Accounts. Public Universities.

v. 21, n. 45,2016 p. $2-20$

ISSN 1518-2924

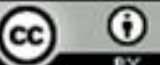

Esta obra está licenciada sob uma Licença Creative Commons. 


\section{INTRODUÇÃO}

A transparência e o livre acesso à informação pública fortalecem a capacidade da sociedade de participar de modo mais efetivo da tomada de decisões que os afeta. Porém, publicar informações em excesso, não significa necessariamente divulgar algo de forma transparente. Uma informação só poderá ser útil para a participação popular, quando for relevante, compreensível, confiável e tempestiva, transformando assim o conceito de transparência mais amplo que o conceito de publicidade (PLATT NETO; CRUZ; VIEIRA, 2006).

Desde a Constituição de 1988, a publicidade das contas públicas foi reconhecida como princípio da administração pública de natureza obrigatória, porém, o governo federal, na tentativa de tornar as contas públicas mais transparentes, tem adotado recentemente, alguns mecanismos legais para auxiliar na busca de uma efetiva política pública de informação.

Porém, a simples existência de textos legais que regulem uma atividade governamental não basta para identificar uma política pública (JARDIM, 2008, p. 5). É necessário que haja um conjunto de projetos, leis e ações do Estado nesse sentido. Diante disso, os instrumentos de transparência, em sua natureza normativa, constitui-se somente um dos aspectos necessários para que ocorra uma efetiva política pública de informação.

Jardim (2012) lembra que foram necessários 23 anos para que o Brasil contasse com uma lei de acesso à informação pública que favorecesse a aplicação dos princípios do direito à informação presentes na Constituição de 1988. Sá e Malin (2012), por sua vez, lembram que democracias mais novas e com adoção mais recente da lei de acesso vêm respondendo melhor à demanda por informações. Porém, constata-se desafios a serem vencidos como a necessidade de criação de um sistema de instituições, processos e práticas jurídicas, políticas, tecnológicas e operacionais, ou seja, desenvolvimento de competências para tratar o enorme volume de informações de forma efetiva, seja por meio de papel ou bases de dados. Além disso, o Estado precisa desenvolver ações para vencer a cultura arraigada de sigilo existente no âmbito do governo (STIGLITZ, 1999; STIGLITZ, 2002; SPECK, 2002; MENDEL, 2009; DAMATTA, 2011).

O uso de portais da internet para disponibilização de informações públicas no Brasil teve inicio com a lei 9.755 de 1998 que foi um marco na transparência das contas públicas. Esse instrumento obrigou o Tribunal de Contas da União a criar uma homepage com o título "contas públicas", divulgando diversas informações de natureza contábil, financeiras e orçamentárias.

Depois disso, vários instrumentos normativos de transparência surgiram com o propósito de obrigar a criação de portais de transparência para divulgação de diversas informações como planos, orçamentos, prestações de contas e o respectivo parecer prévio, entre outros. Entre os instrumentos de transparência estão a Lei Complementar no 101/2000, também conhecida como Lei de Responsabilidade Fiscal (LRF), a Lei 
Complementar n. ${ }^{\circ}$ 131/09, ou Lei da Transparência; o Decreto n.o 7.185/10, e a Lei n. ${ }^{\circ} 12.527 / 11$, a Lei de Acesso à Informação (LAI).

Nesse contexto, as entidades da administração direta e indireta da União, Estados, Distrito Federal e Municípios, conforme obriga a Constituição Federal de 1988, devem prestar contas da utilização dos recursos públicos. Entre as instituições públicas da esfera federal estão as universidades públicas federais, que surgem, comumente, constituídas na forma de autarquias ou fundações e também são obrigadas pela Constituição Federal a prestar contas do uso de seus recursos e dar transparência aos atos públicos. Essas instituições como recebedoras de recursos públicos, tem a obrigação de implementar uma política de transparência com a divulgação das atividades financiadas por esses recursos. E os portais de transparência podem ser a ferramenta adequada para implementar esta política (GALLEGO; GARCÍA; RODRÍGUEZ, 2009)

No contexto da transparência e acesso à informação nas universidades federais, que é o foco dessa pesquisa, existe uma contribuição social. Segundo Oliveira et al. (2013) considerando a missão de geração e disseminação do conhecimento que orienta as universidades, as pesquisas nessa área tornamse relevantes pois geram e disponibilizam conhecimentos no campo de estudo, contribuindo, assim, com a perspectiva de transformação social que o acesso à informação possibilita, cooperando para a formação de cidadãos mais conscientes e participativos.

Pesquisas anteriores já realizadas em universidades públicas no Brasil mostram que existe uma série de limitações na transparência das contas destas instituições. Como, por exemplo, as limitações na transparência das informações dos demonstrativos contábeis das instituições públicas de ensino superior brasileira (LYRIO et al., 2008; BEZERRA; BORGES; VALMORBIDA, 2012); limitações na transparência da prestação de contas da Universidade do Estado de Santa Catarina (ROCZANSKI; TOMASI, 2010); limitações de padrões nos portais das universidades públicas federais relacionados ao conceito de transparência ativa, evidenciado na LAI (RODRIGUES, 2013); falta de práticas de gestão da informação na Universidade Federal de Santa Catarina (SILVA; ALMEIDA, 2013), além da falta de preparação da Fundação Universidade Federal de Rondônia para uma efetiva implementação da LAI (OLIVEIRA et al., 2013).

Diante disso, torna-se necessário compreender melhor o processo de implementação dos normativos que são instrumentos de transparência das contas públicas nestas instituições, a fim de se evitar falhas na operacionalização destas normas.

Assim, com o propósito de contribuir para a melhoria da transparência das contas das universidades públicas, este artigo tem como objetivo analisar o processo de implementação da LAI numa universidade federal brasileira e identificar as perspectivas e desafios dos gestores públicos em relação a esta legislação.

Para tanto, foi utilizada como metodologia uma abordagem qualitativa, que envolve a pesquisa de campo numa universidade federal brasileira, com a coleta de dados realizada por meio da aplicação de questionários, que teve como respondentes os gestores públicos responsáveis por cada divisão e seção dos setores de contabilidade e finanças 
e da ouvidoria geral, que é responsável pela operacionalização da LAI na instituição.

\section{REFERENCIAL TEÓRICO}

\subsection{0 uso da internet para divulgação de informações públicas no Brasil}

A década de 90 foi marcada no Brasil como a década das reformas. Reformar o aparelho estatal e suas instituições apareceu como uma das respostas aos processos de crise fiscal, democratização e globalização dos mercados que se intensificaram nas últimas décadas no país (ABRUCIO; LOUREIRO, 2002; DINIZ et al., 2009). Depois de uma sucessão de programas de estabilização fracassados, desde o Plano Cruzado em 1986 até o Plano Collor em 1990, o Plano Real como um programa de estabilização monetária exitoso desde 1994, livrou o País da hiperinflação (NUNES; NUNES, 2002), o que foi um passo relevante na economia do país, entretanto, uma reforma no aparelho estatal ainda era necessária.

As iniciativas de reforma e modernização do setor público se intensificaram não apenas como consequência da crise fiscal dos anos 1980, mas também como resultado do esgotamento do modelo de gestão burocrática e do modo de intervenção estatal. 0 movimento também conhecido por new public management teve como objetivo a busca da excelência e a orientação dos serviços ao cidadão. Esse movimento baseou-se em princípios gerenciais voltados para resultados, eficiência, governança e orientação da gestão pública para práticas de mercado (DINIZ et al., 2009).

A modernização da gestão pública levava em consideração ainda a divulgação de informações públicas em portais da internet. A introdução da internet no governo brasileiro para divulgação de informações públicas ocorreu no início da década de 90 como parte desse Projeto de Reforma do Estado, em que as ações do governo brasileiro acompanharam o movimento internacional quanto a promoção da qualidade no serviço público (JARDIM, 1999) e do reconhecimento da Internet como a mídia mais interativa e democrática disponível até então (SIMÃO; RODRIGUES, 2005).

As medidas de privatização iniciadas no inicio dos anos 90 e a desregulamentação do sistema de telecomunicação e setores correlatos são percebidas como agentes decisivos do desenvolvimento da internet no país. Em 1991, o Brasil já tinha estabelecido uma ligação com a internet, mas até 1994 pouca coisa tinha acontecido. Somente a partir de 1995, a situação mudou, quando o governo e a economia reconheceram o potencial da internet para suas finalidades (GERMAN, 2000).

No governo, a partir de 1993, vários ministérios começaram a utilizar a rede internet para divulgar informações de sua alçada, com destaque para o Ministério da Fazenda e o Ministério da Administração, além do próprio Ministério da Ciência e Tecnologia (TAKAHASHI, 2000). Porém, não havia um planejamento ou uma norma por parte do governo que incentivasse a divulgação de informações públicas nesse período.

Em 1994, o governo federal criou o Programa de Normalização Técnica para Informática Pública (Nortec*), vinculado ao Sistema de Administração dos Recursos de Informação e Informática (Sisp), com 
objetivo de promover a utilização racional dos recursos de informática e a integração dos sistemas de tratamento da informação no âmbito da administração pública federal direta, autárquica e fundacional (SIMÃO; RODRIGUES, 2005).

Entretanto foi a partir de 1995 que a quantidade de sites do Governo Federal na rede aumentou consideravelmente, e análise independente de princípios de 1996 chegou a apontar o Brasil como o exemplo nas Américas para informações governamentais na Internet. Nos anos seguintes, o acesso às informações no âmbito do Governo Federal, foi sistematizado pelo Ministério do Planejamento, através do portal http:// www.redegoverno.gov.br. (TAKAHASHI, 2000).

Com o desenvolvimento das TICs (tecnologias de comunicação e informação), nas últimas décadas, tem surgido novas possibilidades para a promoção da transparência na administração pública brasileira (VAZ; RIBEIRO; MATHEUS, 2010). Porém, apesar dos avanços do governo brasileiro no uso da internet para evidenciação de informações públicas, cabe ressaltar que é fundamental que o arcabouço legal atenda adequadamente às necessidades geradas pelo emprego dessas tecnologias de informação e comunicação em aplicações de governo, nos aspectos de segurança e autenticação dos documentos; privacidade; padrões técnicos; e viabilização de serviços específicos em novas versões (TAKAHASHI, 2000).

Nesse contexto, o governo federal tem investido na melhoria do arcabouço legal que trata sobre os temas de transparência e acesso às informações públicas. Entre os diversos instrumentos de transparência e de prestação de contas no Brasil, três podem ser considerados verdadeiros marcos na história da Administração Pública brasileira: A Lei n. 9.755, de 16 de dezembro de 1998, que criou na internet o Portal Contas Públicas; a Lei Complementar n. 101, Lei de Responsabilidade Fiscal (LRF), de 4 de maio de 2000, que estabeleceu normas para a gestão fiscal responsável; e o Decreto n. 5.482, de 30 de junho de 2005, que criou na internet o Portal da Transparência (FERREIRA et al., 2014). Porém, ao longo dos últimos anos, outros instrumentos, tais como novas leis, decretos e portarias, ganharam evidencia na tentativa de regulamentar o tema transparência e acesso às informações públicas, como a LC n. ${ }^{\circ} 131 / 09$, o Decreto n. ${ }^{\circ} 7.185 / 10$ e a própria Lei de Acesso a Informação, lei n. ${ }^{\circ}$ 12.527/11.

Diante disso, nota-se que as informações contábeis, financeiras e orçamentárias são objeto de vários instrumentos de transparência por parte do governo brasileiro, e tem se multiplicado nas duas ultimas décadas (dentre eles na lei n. $.^{\circ} 9.755 / 98$, LC 101/00, LC 131/09, e o Decreto 7.185/10). A LAI, em seu artigo $7^{\circ}$, prevê a divulgação obrigatória de tais informações quando afirma que devem ser divulgados, entre outros os repasses ou transferências de recursos financeiros e a execução orçamentária e financeira detalhada, ou seja, informações contábeis.

Este novo instrumento normativo de transparência, a LAI, foi sancionado em novembro de 2011, marca o inicio, de fato, de uma política de acesso às informações públicas com a perspectiva de melhorar a transparência e o controle social, e ainda exige uma série de informações referentes a prestação de contas dos governos. 


\subsection{Implementação da Política de Acesso à Informação: desafios e perspectivas}

De cumprimento obrigatório para todos os entes governamentais, a LAI produz grandes impactos na gestão pública e exigirá, para sua efetiva implementação, a adoção de uma série de medidas. Entre os diversos obstáculos que o país enfrenta na política de acesso à informação, destacamse as dificuldades estruturais e inclusão digital; a cultura do setor público no sigilo da informação e a falta de uma gestão de documentos na administração pública.

Uma pesquisa realizada por Jardim (2012) analisou o cenário histórico-social no qual emerge a Lei de Acesso à Informação Pública no Brasil, assim como as características desse marco legal e sua regulamentação nos Poderes Executivos Federal e nos Estados de Minas Gerais, Paraná, Rio de Janeiro, Rio Grande do Sul e São Paulo. Segundo o autor existe a necessidade de políticas e práticas de gestão informacional associada aos processos de implementação da Lei de Acesso à Informação, supondo uma ordem informacional que está longe de existir no Estado brasileiro.

0 acesso à informação exige tanto a superação dos desafios relativos ao desenvolvimento de redes de telecomunicação e ao acesso democrático a elas; e principalmente, à educação digital da população, isto é, a sua capacitação para usar e manejar os novos meios de comunicação (GONTIJO, 2002).

Segundo Speck (2002) é preciso ainda vencer outro desafio, a cultura do sigilo e propiciar uma cultura de abertura. Em geral, os órgãos públicos temem discussões abertas com a população e a sociedade civil organizada. Os servidores públicos inibem a livre circulação de informações porque temem críticas e obstrução a seus projetos por parte da sociedade. De acordo com Stiglitz (1999) uma maior abertura de informações públicas é parte essencial de uma boa governança.

Para Mendel (2009), no contexto internacional, em vários países, um dos maiores obstáculos do acesso à informação é o péssimo estado de manutenção dos registros. A boa gestão de documentos oficiais não só é essencial para o efetivo estabelecimento do direito a informação, como também é uma das funções básicas do governo moderno, sendo de importância crucial para a efetiva consecução de todas as metas do funcionalismo público.

No Brasil, entre os principais desafios apontados para a implementação da LAI estão: a falta de organização, planejamento e sistematização das informações de cada área; a limitada capacidade de resposta em caso de aumento significativo da demanda por informações; a baixa interoperabilidade dos sistemas e bancos de dados das diferentes áreas e até mesmo dentro de um mesmo órgão; a baixa confiabilidade das bases de dados existentes, motivando temores de que os erros dos sistemas venham a ser utilizados de forma inadequada e danosa para o Estado ou para o governo; e a carência de recursos humanos destinados ao atendimento das solicitações de dados e informações (DAMATTA, 2011).

Porém, apesar dos desafios, deve-se ressaltar, como perspectiva, que a transparência e o acesso às informações tornou-se também uma ferramenta necessária no combate à corrupção. Permite a sociedade saber onde e como o 
dinheiro público está sendo gasto, ou seja, controlar como os recursos públicos estão sendo geridos. Assim, promover a transparência e o acesso à informação é dar condição de acesso a todas as informações sobre a gestão pública, permitindo o controle social.

Para Speck (2002, p. 7) no contexto brasileiro, "as políticas de controle da corrupção propostas nos últimos anos visam melhorar a qualidade dos mecanismos reguladores, para evitar que se azedem as tensões entre país legal e país real com arranjos corruptos." Ao mesmo tempo, dão destaque a integração e a complementação dos diferentes mecanismos de controle, da simples transparência até a sofisticada investigação, mediante a integração das várias iniciativas na esfera pública, social e privada.

Por fim, as estratégias de implementação da Lei devem focar também o fortalecimento dos valores democráticos e a consolidação de uma cultura de abertura e confiança. Certamente, os exemplos de boas práticas existentes, a aliança com as ouvidorias e assessorias de imprensa dos órgãos e a criação de incentivos positivos para a adesão dos corpos técnicos tenderão a contribuir para o sucesso da implementação e a consolidação do direito ao acesso a informação pública no Brasil (DAMATTA, 2011).

\section{METODOLOGIA}

Trata-se de uma pesquisa com abordagem qualitativa, que utilizou a pesquisa bibliográfica e a pesquisa de campo. Como objeto da pesquisa de campo foi escolhida a Universidade Federal do Espírito Santo (UFES), que se encontra entre as dez universidades que mais registraram pedidos de informação por meio do portal do e-SIC (Sistema Eletrônico do Serviço de Informações ao Cidadão) do governo federal, tanto no primeiro quanto no segundo ano de implementação da LAI, conforme dados levantados dos Relatórios Estatísticos deste sistema.

Como instrumentos para a coleta de dados foram aplicados questionários com questões fechadas, semiestruturadas. Os respondentes foram os gestores públicos da UFES responsáveis por cada seção e divisão do Departamento de Contabilidade e Finanças (DCF) e da Ouvidoria Geral. No total a pesquisa contou com uma população de oito gestores públicos. Sendo seis chefes de seção ou divisão, lotados no Departamento de Contabilidade e Finanças - DCF; e dois chefes de seção da Ouvidoria Geral, responsáveis pela LAI na instituição. Os respondentes equivalem a toda população de gestores lotadas nestes departamentos.

A seleção destes setores justifica-se pelo fato de que o departamento de contabilidade é o setor responsável pelo registro de todas as contas da instituição, além de gerar grande parte das informações e relatórios para serem divulgados no portal de transparência da instituição e no portal de transparência mantido pelo governo federal. E a Ouvidoria Geral, por sua vez, é o setor responsável por registrar todas as demandas de informações surgidas após a LAI.

O questionário aplicado ao DCF procurou identificar os demandantes por informações das contas públicas e a frequência da demanda; analisou também o uso do portal de transparência do governo federal pelos gestores 
da UFES, além do conhecimento desses respondentes em relação as legislações de transparência do governo federal. 0 questionário direcionado a Ouvidoria Geral, por sua vez, analisou o processo de implementação da LAI, como instrumento de transparência, na universidade. Ambos os questionários analisaram as perspectivas e desafios dos gestores da UFES, em relação a implementação da LAI na instituição.

Para isto, os questionários foram desenvolvidos em três partes. Sendo para os gestores do DCF: Bloco I - Perfil dos respondentes; Bloco II Instrumentos de Transparência; e Bloco III - Perspectivas e Desafios em relação à LAI. E para os gestores da Ouvidoria Geral da UFES: Bloco I - Perfil dos respondentes; Bloco II - Implementação da LAI; e Bloco III - Perspectivas e Desafios em relação à LAI. Registra-se que o único bloco diferente nos questionários refere-se ao Bloco II.

O Bloco I conta com três perguntas, sendo duas perguntas referentes ao tempo no cargo e escolaridade do respondente, e sua área de formação.

O Bloco II foi elaborado de forma diferente, sendo um para o DCF e outro para a Ouvidoria Geral. No caso do DCF (Instrumentos de Transparência), o questionário foi composto por seis questões fechadas, que analisaram: 1. A frequência da demanda; 2 . A quantificação da frequência; 3. Os usuários da informação; 4. O grau de conhecimento em relação às legislações de transparência; 5. 0 grau de conhecimento do portal de transparência da UFES; e 6. A qualidade das informações do portal de transparência da UFES. No caso da Ouvidoria Geral, o Bloco II (Implementação da LAI), foi composto por dez questões, que envolveram: 1. 0 desenvolvimento de um plano de ação; 2. As práticas de gestão da informação; e 3. Os sistemas de informação existentes para atendimento das leis de transparência.

Para a elaboração do Bloco III dos questionários (Desafios e Perspectivas em relação à LAI), as questões tiveram como base o documento da Controladoria Geral da União, desenvolvido por Damatta (2011) Intitulado "Sumário Executivo. Pesquisa Diagnóstico sobre Valores, Conhecimento e Cultura de Acesso à Informação Pública no Poder Executivo Federal Brasileiro". Foi analisado um total de doze perspectivas e doze desafios.

A escala utilizada para o Bloco III foi: a) Perspectivas: Como você classifica suas perspectivas em relação à implementação da LAI, de um grau de 1 a 4 , sendo 1 um fato impossível de ocorrer e 4 um fato que com certeza irá ocorrer. E b) Desafios: Como você classifica os desafios em relação à implementação da LAI, de um grau de 1 a 4, sendo 1 um fato impossível de ocorrer e 4 um fato que com certeza irá ocorrer.

\section{ANÁLISE DE DADOS: RESULTADOS DA PESQUISA DE CAMPO NA UFES}

Esta seção foi separada em três partes referentes à análise dos três blocos dos questionários aplicados. Sendo: Bloco I - Perfil dos respondentes; Bloco II - Instrumentos de Transparência (DCF) e Implementação da LAI (Ouvidoria Geral); e Bloco III - Perspectivas e Desafios em relação à LAI.

Os respondentes foram os gestores do DCF da UFES, que corresponderam a seis chefes de seção ou divisão dos seguintes: 1. Divisão de 
Contabilidade e 1.1. Seção de Análise e Controle Contábil; 2. Divisão de Administração Financeira, 2.1. Seção de Análise e Controle Orçamentário, 2.2. Seção de Orçamento e Finanças, 2.3. Seção de Controle Financeiro. E os dois gestores responsáveis pela LAI na instituição, ligados à Ouvidoria Geral.

Os questionários foram aplicados no período de 25 de março de 2015 a 20 de maio de 2015. Sendo que, todos os questionários aplicados foram respondidos, correspondendo assim, a população total de gestores destes departamentos.

\section{Bloco I: Perfil dos Respondentes}

O bloco I corresponde ao perfil dos respondentes, referentes ao tempo no cargo, escolaridade do respondente, e sua área de formação.

Os resultados mostram que 70\% dos gestores do DCF está há mais de cinco anos no setor, sendo que destes, 30\% estão no setor há mais de 15 anos. Além disso, cerca de $70 \%$ possuem especialização com pós-graduação ou mestrado. Quanto à área de formação, todos os gestores encontram-se nas áreas de ciências contábeis e administração.

Já o perfil dos dois gestores responsáveis pela LAI na instituição mostra que ambos são doutores, nas áreas de administração de empresas e engenharia elétrica, e estão no cargo no período entre 5 e 10 anos. Um gestor encontra-se responsável pelo cargo de Ouvidor Geral e o outro no cargo de Diretor do Núcleo de Processamento de Dados da UFES.

\section{Bloco II: Instrumentos de Transparência (DCF)}

O Bloco II procurou analisar a demanda por informações das contas públicas registradas no DCF da UFES, além de identificar os demandantes e a frequência da demanda; analisou também o uso dos portais de transparência pelos gestores da UFES, criados por leis anteriores ou pela própria LAI, e o conhecimento desses respondentes em relação as legislações de transparência do governo federal. Os conceitos analisados e a escala utilizada para medida de cada conceito estão apresentadas no Quadro 1.

Quadro 1: Conceitos e escalas do Bloco II do questionário aplicado ao DCF

\begin{tabular}{|c|c|}
\hline Conceito analisado & Escala de medida \\
\hline 1. Frequência da Demanda & 1. Não existe; 2. Permanente; 3.Sazonal \\
\hline 2. Quantificação da Frequência & 1. Baixa; 2. Normal; 3. Alta \\
\hline 3. Usuários demandantes & 1. Interna; 2. Externa; 3. Ambas \\
\hline 4. Demanda em números de atendimento & $\begin{array}{l}\text { 1. Até } 3 \text { ao dia; } 2 \text {. De } 4 \text { ou mais ao dia; } 3 \text {. Até } 3 \text { por } \\
\text { semana; } 4 \text {. De } 4 \text { ou mais na semana; e } 5 \text {. Algumas } \\
\text { vezes no mês }\end{array}$ \\
\hline $\begin{array}{l}\text { 5. Grau de conhecimento da legislação (LC 101/2000, } \\
\text { Dec. 5.432/05, LC 131/09, Lei } 12.527 / 11 \text {, Dec. } \\
\text { 7.724/12) }\end{array}$ & 1. Nenhum; 2. Baixo; 3. Médio; 4. Alto. \\
\hline 6. Grau conhecimento dos portais de transparência & $\begin{array}{l}\text { 1. Desconheço; } 2 \text {. Conheço, mas não consulto; } 3 \text {. } \\
\text { Consulto sempre que preciso. }\end{array}$ \\
\hline 7. Qualidade da informação no portal & 1. Ruim; 2. Suficiente; 3. Boa \\
\hline
\end{tabular}

Fonte: Elaborada pela autora. 
Os resultados mostram que:

1) Sobre a frequência da demanda por informação das contas públicas: A frequência é permanente para $83 \%$ dos gestores respondentes, ou seja, a procura por informações contábeis ocorre durante todo o ano e não somente em determinada época;

2) Sobre a quantificação da frequência da demanda por informação das contas públicas: A percepção sobre demanda por setor encontra-se entre normal ou alta, na percepção dos respondentes. Sendo que, $70 \%$ dos respondentes afirmam realizar mais de quatro atendimentos ao dia;

3) Sobre os demandantes da informação: Os usuários responsáveis por gerar essa demanda são tanto internos quanto externos, ou seja, os demandantes são servidores públicos da própria instituição, fornecedores e a sociedade em geral;

4) Sobre o grau de conhecimento dos gestores em relação a legislação de transparência das contas públicas: 0 grau de conhecimento dos respondentes da legislação sobre transparência das contas públicas (LC n. ${ }^{\circ}$ 101/2000, Decreto n. ${ }^{\circ}$ 5.432/05, LC 131/09, Lei n. ${ }^{\circ} 12.527 / 11$, Decreto n. ${ }^{\circ} 7.724 / 12$ ) está entre baixo e médio. Ressalta-se um dos gestores respondentes afirma desconhecer todas as legislações sobre transparência pública. 0 que demonstra que apesar de muitas informações já constarem nos portais do governo de forma obrigatória pela legislação de transparência, existe certa falta de conhecimento de alguns servidores para incentivar que os demandantes consultem a página de transparência da universidade ou $o$ portal da transparência do governo federal, para obterem tais informações;

5) Sobre o conhecimento dos gestores em relação aos portais de transparência do governo: $83 \%$ dos respondentes afirmam conhecer a existência dos portais de transparência do governo federal e da própria instituição, criados pelo Decreto n. ${ }^{\circ} 5.432 / 05$, pela LC 131/09, ou pela Lei n. ${ }^{\circ}$ $12.527 / 11$, porém, não possuem o hábito de consultá-los. Este resultado pode ser consequência da atualização dos dados em períodos mensais, quinzenais e semanais, e não diário. Porém, se os próprios gestores não costumam consultar as informações dos portais, parece difícil que haja incentivo para que os demandantes por informação contábil realizem esta consulta. Além disso, apesar do aumento das leis de transparência para criação de portais, existe no Brasil a cultura do sigilo que parece incentivar aos demandantes a buscar a informação diretamente no órgão;

6) Sobre a qualidade da informação contida no portal de transparência do governo: Somente $20 \%$ dos gestores respondentes afirmam que a qualidade da informação do portal é considerada muito boa. Todos os outros consideram que é suficiente. Este fato pode explicar a falta de hábito dos gestores de consultar os portais do governo. Registra-se que as características que definem a qualidade da informação contábil são atributos da informações que tendem a ampliar sua utilidade.

Deve-se ressaltar que para a implementação dos portais de transparência o governo federal disponibiliza algumas informações das contas públicas por meio das Páginas de Transparência, que no caso da UFES pode ser acessada pelo link <http://www3.transparencia.gov.br/TransparenciaPublica/index.jsp?Codigo 
Orgao $=26234 \&$ TipoOrgao $=2>$. Porém, este portal não é atualizado em tempo real, e muitas informações precisam estar evidenciadas no portal da própria instituição, por força de lei, como por exemplo, da LAI. A UFES possui um Portal que atende à Lei de Acesso à Informação. Este canal é mantido e administrado pela própria instituição.

Com base nos resultados, pode-se afirmar que é necessário mais ações por parte do governo federal para incentivar o uso dos portais de transparência pelos servidores e gestores públicos.

\section{Bloco II: Implementação da LAI (Ouvidoria Geral)}

O Bloco II buscou analisar o processo de implementação da LAI na instituição. E para isto, abordou temas de gestão da informação, e a utilização dos sistemas de informação para operacionalização da LAI e demais instrumentos de transparência.

O gestor responsável pela implementação da LAI na UFES, afirma que houve um plano de ação e uma comissão formada por três servidores para desenvolver um sistema informatizado que serviria como porta de entrada e divulgação das informações na universidade. Segundo esse gestor, o sistema chegou a ser desenvolvido, mas não foi utilizado por que dias depois o governo federal disponibilizou o e-SIC que deveria ser utilizado por todas as entidades públicas federais. Logo após o desenvolvimento e entrega do sistema o gestor responsável pela comissão deixou a função de responsável pela LAI na UFES que foi assumida pelo Ouvidor atual. As respostas dos dois gestores, ouvidor geral (gestor 1) e responsável pela implementação da LAI (gestor 2), estão apresentadas no Quadro 2.

Quadro 2: Respostas sobre o plano de ação para implementação da LAI

\begin{tabular}{|l|c|c|}
\hline \multicolumn{1}{|c|}{ A) Desenvolvimento de um plano de ação para implementação da LAI } & Gestor 1 & Gestor 2 \\
\hline A1) Foram identificadas necessidades e estabelecidas metas. & 2 & 4 \\
\hline A2) Foram identificados os desafios e obstáculos para implementação da LAI. & 2 & 3 \\
\hline $\begin{array}{l}\text { A3) Foram identificados quais os tipos de informações que poderiam ser mais } \\
\text { frequentemente solicitadas. }\end{array}$ & 2 & 3 \\
\hline A4) Foi verificado se há informação em formatos de difícil acesso. & 1 & 4 \\
\hline $\begin{array}{l}\text { A5) Foi verificado que informações a universidade pode divulgar proativamente } \\
\text { (além do rol mínimo exigido pela lei) }\end{array}$ & 3 & 3 \\
\hline $\begin{array}{l}\text { A6) Considero os Sistemas de Informação da universidade eficientes para o } \\
\text { atendimento da LAI e demais instrumentos de transparência. }\end{array}$ & 3 & 2 \\
\hline $\begin{array}{l}\text { A7) Considero que a gestão das informações é padronizada e coordenada entre os } \\
\text { setores e departamentos. }\end{array}$ & 2 & 2 \\
\hline $\begin{array}{l}\text { A8) Realizei os treinamentos necessários sobre a LAI para iniciar meu trabalho } \\
\text { com eficiência. }\end{array}$ & & \\
\hline $\begin{array}{l}\text { A9) Considero ter todos os instrumentos de suporte tecnológico para realizar } \\
\text { minhas atividades na universidade. }\end{array}$ & 3 & 1 \\
\hline $\begin{array}{l}\text { A10) Considero ter todos os instrumentos de suporte de recursos humanos para } \\
\text { realizar minhas atividades na universidade. }\end{array}$ & 2 & 2 \\
\hline
\end{tabular}

Fonte: Elaborado pelas autoras com base nos dados da pesquisa. 
Pode-se perceber que as respostas dos dois gestores são diferentes em relação aos itens analisados, exceto as perguntas A5 e A7. A divergência entre eles é explicada pelo fato da instituição ter criado uma comissão de implementação da LAI com o objetivo de apoiar o desenvolvimento do sistema que iria servir para operacionalizar a lei na UFES, porém, logo após o sistema estar pronto, o governo federal, obrigou o uso do e-SIC, e todo o trabalho realizado pela comissão foi abandonado. Segundo o gestor responsável pela implementação da LAI na UFES, houve uma desmotivação dos envolvidos pelo assunto, inclusive pela equipe do Núcleo de Processamento de Dados - NPD, que desenvolveu o sistema. Assim, a passagem da etapa de implementação (gestor 2) para a etapa de operacionalização (gestor 1) ficou prejudicada.

Ressalta-se que os dois gestores consideram que a gestão das informações na universidade não é padronizada e coordenada entre os setores e departamentos. Este fato já foi identificado pela universidade que criou o Departamento de Gestão da Informação, da Pró-Reitoria de Planejamento e Desenvolvimento Institucional (Proplan), porém, o departamento de gestão da informação da universidade não possui relação com a implementação da LAI, o que parece ser contrassenso dada a importância da gestão da informação para a política de acesso a informação. Já sobre os sistemas de informação utilizados pela universidade, deve-se ressaltar que como uma entidade autárquica federal, utiliza obrigatoriamente os sistemas disponibilizados pelo governo federal, como no caso do e-SIC disponibilizado pela CGU para operacionalização da LAI. Na percepção dos respondentes os sistemas de informação da universidade são suficientes para atendimento da LAI e outros instrumentos de transparência.

\section{Bloco III - Perspectivas e Desafios em relação à LAI}

O Bloco III procurou analisar a percepção dos gestores do DCF e da Ouvidoria Geral sobre as perspectivas e os desafios de implementação da lei. Foram listadas doze perspectivas e doze desafios com quatro opções de resposta.

Neste bloco, optou-se por trabalhar com a média das respostas dos gestores, que foram apresentadas nos Quadros 3 e 4, em ordem decrescente. A percepção dos gestores foi medida num grau de 1 a 4 , sendo 1 para um fato impossível de ocorrer e 4 um fato que com certeza irá ocorrer.

Os resultados mostram que das perspectivas dos gestores respondentes o item que parece ter mais chances de se realizar foi: mais transparência nas contas públicas (contratos, balanços, relatórios de auditoria, etc.); e o item que, segundo os respondentes, é mais difícil de ocorrer com a implementação da LAI e recebeu menor pontuação média foi o aumento da satisfação no trabalho, como apresentado Quadro 3. 
Quadro 3: Análise das perspectivas dos respondentes em relação a implementação da LAI

\begin{tabular}{|l|c|}
\hline \multicolumn{1}{|c|}{ Perspectivas } & Média \\
\hline Mais transparência nas contas públicas (contratos, balanços, rel. de auditoria, etc.) & 4,0 \\
\hline Mais transparência sobre as atividades da Administração Pública & 3,0 \\
\hline Redução, combate e prevenção da corrupção & 3,0 \\
\hline Melhoria no uso dos recursos públicos por parte dos gestores & 3,0 \\
\hline Uso da Informação pelo gestor público, em tempo real, para tomada de decisão & 3,0 \\
\hline Aumento do Controle Social & 2,0 \\
\hline Conscientização do servidor público quanto ao seu papel & 2,0 \\
\hline Fortalecimento da credibilidade da Administ. Pública frente aos org. internacionais & 2,0 \\
\hline Aproximação entre o cidadão e a Administração Pública & 2,0 \\
\hline Maior respeito aos direitos humanos & 2,0 \\
\hline Aumento da confiança do cidadão na Administração Pública & 2,0 \\
\hline Aumento da sua satisfação no trabalho. & 1,0 \\
\hline
\end{tabular}

Fonte: Elaborado pela autora com base nos dados da pesquisa.

Em relação aos desafios com a implementação da LAI, os resultados mostram que conforme resposta dos gestores o item que parece ser o maior desafio é a falta de infraestrutura dos sistemas de informação e demais tecnologias. Nota-se que os demais itens, salvo uma exceção referente a falta de recursos humanos, foram apontados com nota média 3,0, ou seja, considerados desafios com grande probabilidade de ocorrência na opinião dos respondentes e sinalizando a preocupação dos gestores com esses possíveis problemas. 0 resultado é apresentado no Quadro 4 que apresenta os resultados da média das respostas por item analisado, classificados da maior para a menor pontuação média, em relação aos desafios com a implementação da LAI.

Quadro 4: Análise dos desafios dos respondentes em relação a implementação da LAI

\begin{tabular}{|l|c|}
\hline \multicolumn{1}{|c|}{ Desafios } & Média \\
\hline Falta de infraestrutura dos sistemas de informação e demais tecnologias & 4,0 \\
\hline Uso político das informações obtidas & 3,0 \\
\hline $\begin{array}{l}\text { Vantagens desproporcionais e indevidas para grupos de interesses bem situados para obter } \\
\text { essas informações e usá-las para seus fins privados }\end{array}$ & 3,0 \\
\hline Aumento da carga de trabalho do servidor público & 3,0 \\
\hline Falta de treinamentos para a execução do trabalho & 3,0 \\
\hline Má utilização das informações obtidas & 3,0 \\
\hline Uso indevido dessas informações pela imprensa & 3,0 \\
\hline Solicitações excessivas e descabidas & 3,0 \\
\hline Mais conflitos entre o cidadão e a Administração Pública & 3,0 \\
\hline Maior burocratização ("emperramento da máquina”) da Administração Pública & 3,0 \\
\hline Alienação e desmotivação do servidor público & 3,0 \\
\hline Falta de recursos humanos para execução do trabalho & 2,0 \\
\hline
\end{tabular}

Fonte: Elaborado pela autora com base nos dados da pesquisa. 
0 item que recebeu menor pontuação, sinalizando um menor desafio, foi o referente a falta de recursos humanos para a execução dos trabalhos, o que pode sinalizar que a universidade possui quantitativo de mão de obra apesar de assumir que precisa de treinamentos.

Os resultados encontrados nesta pesquisa confirmam os resultados de pesquisas anteriores realizadas em outras universidades públicas no Brasil, que apresentam uma série de limitações na transparência das contas destas instituições (LYRIO et al., 2008; ROCZANSKI; TOMASI, 2010; BEZERRA; BORGES; VALMORBIDA, 2012; RODRIGUES, 2013; SILVA; ALMEIDA, 2013; OLIVEIRA et al., 2013).

As limitações aqui destacadas confirmam que é necessário haver mais ações por parte do governo, além de leis e construção de portais. Os portais de transparência precisam ser melhorados, pois é um instrumento facilitador do controle social. Porém, vale lembrar, que "a Internet em si não trará mais participação política; ela não foi desenvolvida para ser um instrumento facilitador da cidadania, apesar de poder, de fato, modificar a participação política e dispor de um potencial democratizador" (SPECK, 2002).

\section{CONSIDERAÇÕES FINAIS}

Este artigo teve como objetivo analisar o processo de implementação da LAI na UFES e identificar as perspectivas e desafios dos gestores públicos em relação a esta legislação.

Os resultados mostram que sobre o processo de implementação da LAI, foi realizado um plano de ações para o desenvolvimento de um sistema que atendesse a lei, porém, este não foi implementado até o final, pois o governo federal disponibilizou no ultimo momento o sistema, e-SIC, que deveria ser utilizado por todos os órgãos do executivo federal. Este plano não foi repassado ao ouvidor geral, gestor responsável por operacionalizar a LAI na instituição, e apesar de não implementado, demonstra falha na comunicação entre os envolvidos no processo. Além disso, faltou apoio do Departamento de Gestão da Informação, criado recentemente na universidade.

Ressalta-se que os gestores consideram que a gestão da informação na universidade não é padronizada e coordenada entre os setores e departamentos, e necessita de melhorias. Porém, este fato já foi identificado pela instituição que criou o Departamento de Gestão da Informação, da PróReitoria de Planejamento e Desenvolvimento Institucional (Proplan). Entretanto, deve-se registrar que o departamento de gestão da informação da universidade não possui relação com a implementação da LAI, o que parece ser contrassenso dada a importância da gestão da informação para a política de acesso a informação.

Esta pesquisa identificou ainda as perspectivas e os desafios dos gestores da UFES em relação à LAI. Os resultados apontam que em relação às perspectivas, o item que parece ter mais chances de se realizar foi: mais transparência nas contas públicas (contratos, balanços, relatórios de auditoria, etc.); e o item que, segundo os respondentes, é mais difícil de 
ocorrer com a implementação da LAI e recebeu menor pontuação média foi o aumento da satisfação no trabalho. Outros itens que receberam pontuação baixa foram: i) aumento do controle social; ii) conscientização do servidor público quanto ao seu papel; iii) fortalecimento da credibilidade e melhoria da imagem da Administração Pública frente aos organismos internacionais; iv) aproximação entre o cidadão e a Administração Pública; v) maior respeito aos direitos humanos; e vi) aumento da confiança do cidadão na Administração Pública. 0 que demonstra que, na opinião dos gestores, o governo precisa investir em outras ações, além da lei, para que estes fatos se tornem realidade.

Estes resultados confirmam estudos de autores que afirmam que o Estado precisa desenvolver ações para vencer a cultura arraigada de sigilo existente no âmbito do governo e incentivar a cultura de abertura (STIGLITZ, 1999; STIGLITZ, 2002; SPECK, 2002, MENDEL, 2009, DAMATTA, 2011).

Em relação aos desafios com a LAI na UFES, os resultados mostram que conforme resposta dos gestores do DCF e da ouvidoria, o item que parece ser o maior desafio é a falta de infraestrutura dos sistemas de informação e demais tecnologias. Nota-se que os demais desafios analisados, salvo uma exceção referente a falta de recursos humanos, foram considerados desafios com grande probabilidade de ocorrência na opinião dos respondentes e sinalizando a preocupação dos gestores com esses possíveis problemas. Entre eles estão: Vantagens desproporcionais e indevidas para grupos de interesses bem situados para obter essas informações e usá-las para seus fins privados; aumento da carga de trabalho do servidor público; falta de treinamentos para a execução do trabalho; má utilização das informações obtidas; uso indevido dessas informações pela imprensa; e solicitações excessivas e descabidas.

Este resultado confirma o estudo realizado por Damatta (2011) que afirma que além dos desafios relativos à mudança da cultura do segredo para uma cultura de abertura, há também obstáculos operacionais e técnicos. As práticas da administração são bastante diversas no que tange à gestão de informações. Enquanto algumas áreas já possuem sistemas de informação e bancos de dados modernos, outras ainda permeiam na era do papel, enfrentando dificuldades para localizar documentos e controlar o fluxo de pedidos e de respostas. Uniformizar esta realidade exigirá recursos financeiros e recursos humanos na área de Tecnologia da Informação.

Pode-se, então, afirmar que a transparência pública no Brasil ainda é processo em fase inicial, e que depende da contribuição de todos os atores envolvidos. A edição de instrumentos de transparência, como a LAI é um passo importante, mas não pode ser único. A melhoria dos portais de transparência e a melhoria da infraestrutura de recursos técnicos e humanos da administração pública, aliada a ações do governo para alcançar uma cultura de abertura e acesso ao invés do sigilo, pressupõe um avanço na transparência pública a médio ou longo prazo.

Conclui-se que apesar do esforço do Governo Federal em editar instrumentos normativos sobre transparência das contas públicas para evidenciação de informações públicas nos portais, não foram identificadas outras ações, além da disponibilização de um sistema de informação, e-SIC, para administrar essas demandas, que auxiliem as entidades públicas para 
efetiva implementação destes instrumentos. Desta forma, diante da falta de apoio do governo, cada instituição deve planejar e promover suas próprias ações neste sentido.

Talvez essa pesquisa possa ser repetida futuramente com o intuito de identificar se os desafios identificados foram vencidos e as perspectivas foram alcançadas no processo de operacionalização da LAI e demais instrumentos de transparência.

\section{REFERÊNCIAS}

ABRUCIO, Fernando Luiz; LOUREIRO, Maria Rita (coordenadores). 0 Estado Numa Era de Reformas: Os Anos FHC - Parte 1. Brasília : MP, SEGES, 2002.

BORBOREMA, Ernani Avelar; RIBEIRO, Cyro Castilho. A Homepage Contas Públicas: Um Diagnóstico de Contribuição para o Controle Social. 2006. Disponível em:

<http://portal2.tcu.gov.br/portal/pls/portal/docs/2053966.PDF>. Acesso em 04 mar. 2010.

BECKER, Maria Lucia. Inclusão digital e governo eletrônico no Brasil: após 20 anos, muitos desafios. Revista Ação Midiática - Estudos em Comunicação, Sociedade e Cultura, n. 6, 2013. Disponível em: <http://ojs.c3sl.ufpr.br/ojs/index.php/acaomidiatica/article/viewFile/3437 6/21919>. Acesso em 04 mar. 2010.

BEZERRA, R. O.; BORGES, L. J.; VALMORBIDA, S. M. L..Análise das prestações de contas na internet da Universidade do Estado de Santa Catarina. Revista GUAL, v. 5, n. 1, p. 66-82, 2012. Disponível em: $<$ https://periodicos.ufsc.br/index.php/gual/article/view/19834535.2012v5n1p66>. Acesso em: 01 mai. 2014.

DAMATTA, R. (coord.). Sumário Executivo: Pesquisa Diagnóstico sobre Valores, Conhecimento e Cultura de Acesso à Informação Pública no Poder Executivo Federal Brasileiro. Brasília: 2011. Disponível em:

$<$ http://www.acessoainformacao.gov.br/central-deconteudo/publicacoes/arquivos/pesquisadiagnostico.pdf > . Acesso em: 21 mar. 2013.

DINIZ, et. al. 0 governo eletrônico no Brasil: perspectiva histórica a partir de um modelo estruturado de análise. RAP, v. 43, n. 1, p. 23-48, 2009. Disponível em <http://www.scielo.br/scielo.php?script=sci arttext\&pid=S003476122009000100003 >. Acesso em: 20 mar. 2015.

FERREIRA, C. D et al. Accountability da gestão pública municipal na região sudeste e a adequação à lei complementar 131/2009. In: CONGRESSO USP DE INICIAÇÃo CIENTÍFICA EM CONTABILIDADE, 11., São Paulo, 2014. Anais... São Paulo: USP, 2014. Disponível em: 
<http://congressousp.fipecafi.org/web/artigos142014/497.pdf > . Acesso em: 2 jul. 2014.

GALLEGO, I; GARCÍA, I. M; RODRÍGUEZ, L. Universities' Websites: Disclosure Practices and the Revelation of Financial Information. The International Journal of Digital Accounting Research, v. 9, p. 153-192, 2009.

GERMAN, C. 0 caminho do Brasil rumo à era da informação. São Paulo: Fundação Konrad Adenauer, 2000.

GONTIJO, M. Análise da proposta brasileira de e-governo como expressão de uma política de informação a partir do conceito de regime de informação. Perspectivas em Ciência da Informação, v. 7, n. 2, p. 179-188, jul./dez. 2002. Disponível em: <http://www.eci.ufmg.br/ pcionline/index.php/pci/article/viewFile/406/217>. Acesso em: 2 jul. 2014.

JARDIM, J. M. Transparência e opacidade do estado no Brasil : usos e desusos da informação governamental. Niterói : EdUFF, 1999.

Políticas públicas de informação: a (não) construção da política nacional de arquivos públicos e privados (1994-2006). In: ENCONTRO NACIONAL DE PESQUISA EM CIÊNCIA DA INFORMAÇÃO, 9., 2008, São Paulo. Anais... São Paulo: Ancib, 2008. Disponível em: <http://www.contagem.mg.gov.br/arquivos/arquivos/infotec/jardimpolitic as publicas de informacao.pdf>. Acesso em: $21 \mathrm{fev} .2014$.

Lei de Acesso à informação pública: dimensões políticoinformacionais. Comunicação oral. In: ENCONTRO NACIONAL DE PESQUISA EM CIÊNCIA DA INFORMAÇÃO, 13., 2012, Rio de Janeiro. Anais... Rio de Janeiro: Ancib, 2012. Disponível em: <http://inseer.ibict.br/ancib/index.php/tpbci/article/viewArticle/68>. Acesso em: 2 ago. 2014.

A implantação da Lei de Acesso à Informação Pública e a gestão da informação arquivística governamental. Liinc em Revista, v. 9, n. 2, p. 383405, 2013. Disponível em: <http://www.ibict.br/liinc>. Acesso em: 5 out. 2014.

LYRIO, M.V.L. et al. Proposta de um modelo para avaliar o grau de transparência das demonstrações financeiras publicadas por uma instituição pública de ensino superior brasileira: a abordagem da metodologia multicritério de apoio à decisão construtivista: contabilidade, gestão e governança. Revista UnB Contábil, v. 11, n. 1-2, p. 170-186, 2008.

MALIN, A. M. B.: Reflexões sobre a adesão brasileira ao Regime Global de Acesso à Informação Pública. In: ENCONTRO NACIONAL DE PESQUISA EM CIÊNCIA DA INFORMAÇÃO, 13., 2012, Rio de Janeiro. Anais... Rio de Janeiro: Ancib, 2012. Disponível em: <http://obgi.org/wpcontent/uploads/2013/08/Produção-Intelectual-2012-Reflexões-sobre-a- 
adesão-brasileira-aoregime-global-de-acesso-à-informação-pública.pdf> . Acesso em: 02 mar. 2015.

MENDEL, Toby. Freedom of Information: A Comparative Legal Survey. UNESCO: Paris, 2008. Disponível em $<$ http://unesdoc.unesco.org/images/0015/001584/158450e.pdf>. Acesso em: 10 mar 2013.

NUNES, S. P. P.; NUNES R. da C. 0 Processo Orçamentário na Lei de Responsabilidade Fiscal: instrumento de planejamento. In: FIGUEIREDO, C. M.; NÓBREGA, M. (Org.). Administração Pública: direitos administrativos, financeiros e gestão pública: prática, inovações e polêmicas. São Paulo: Revista dos Tribunais, 2002. 34p. Disponível em: $<$ http://www.uberaba.mg.gov.br/portal/acervo/orcamento/boletins/O Proc esso orcamentario na LRF instrumento de planejamento.pdf $>$. Acesso em: 02 mar. 2015.

OLIVEIRA, C. M. et al. Transparência e Acesso a Informação: os desafios enfrentados na implementação sa Lei no 12.527 na Fundação Universidade Federal de Rondônia. In: XIII COLOQUIO DE GESTIÓN UNIVERSITARIA EN AMÉRICAS. Anais....Florianópolis, 2013.

PLATT NETO, O. A.; CRUZ, F.; VIEIRA, A. L. A evolução das práticas de uso da internet para divulgação das contas públicas na Universidade Federal de Santa Catarina. In: COLÓQUIO INTERNACIONAL SOBRE GESTÃO UNIVERSITÁRIA NA AMÉRICA DO SUL, 9., Florianópolis. Anais... Florianópolis, 2009.

PLATT NETO, O. A.; CRUZ, F.; VIEIRA, A. L. Transparência das Contas Públicas: um enfoque no uso da Internet como instrumento de publicidade na UFSC. Revista Contemporânea de Contabilidade, v. 1, n. 5, p. 135-146, 2006.

RIBEIRO, C. J. PEREIRA, D. V. A publicação de dados governamentais abertos: proposta de revisão da classe sobre Previdência Social do Vocabulário Controlado do Governo Eletrônico. TransInformação, v. 27, n. 1, p. 73-82, 2015. Disponível em <http://www.scielo.br/pdf/tinf/v27n1/0103-3786tinf-27-01-00073.pdf >. Acesso em: 05 maio 2015.

ROCZANSKI, C. R. M.; TOMASI, M. Universidade Pública e Accountability. In: CONGRESSO CONSAD DE GESTÃO PÚBLICA, III, 2010. Painel 45., Brasília/DF. Anais... Brasília: Consad, 2010. Disponível em: $<$ http://www.escoladegoverno.pr.gov.br/arquivos/File/Material \%20CONS AD/paineis III congresso consad/painel 45/universidade publica e account ability.pdf > . Acesso em: 27 jan. 2013.

RODRIGUES FILHO, J. LUDMER, G. Sistema de informação: Que ciência é essa? Revista de Gestão da Tecnologia e Sistemas de Informação, v. 2, n. 2, p. 151-166, 2005. 
RODRIGUES, G. M. Indicadores de "transparência ativa" em instituições públicas: análise dos portais de universidades públicas federais. Liinc em Revista, v. 9, n. 2, p. 423-438, 2013. Disponível em <http://www.ibict.br/liinc>. Acesso em: 03 mar. 2014.

SÁ, M. I. da F.; MALIN, A. M. B. Lei de Acesso à Informação: um estudo comparativo com outros países. ENCONTRO NACIONAL DE PESQUISA EM CIÊNCIA DA INFORMAÇÃO, 13., 2012, Rio de Janeiro. Anais... Rio de Janeiro: Ancib, 2012. Disponível em: $<$ http://enancib.ibict.br/index.php/enancib/xiiienancib/paper/viewFile/37 76/2899>. Acesso em: 11 set. 2014.

SPECK, B. W. (org.). Caminhos da Transparência. Campinas: Unicamp, 2002. SILVA, E. C. R.; ALMEIDA, M. de S. A Gestão da Informação na Universidade Federal de Santa Catarina sob a abordagem da ecologia da informação. In: COLOQUIO DE GESTIÓN UNIVERSITARIA EN AMÉRICAS, 13., Florianópolis. Anais... Florianópolis, 2013.

SIMÃO, João Batista; RODRIGUES, Georgete. Acessibilidade às informações públicas: uma avaliação do portal de serviços e informações do governo federal. Ciência da Informação, v. 34, n. 2, p. 81-92, 2006. Disponível em <http://www.scielo.br/pdf/ci/v34n2/28558.pdf> Acesso em: 25 fev. 2007.

STIGLITZ, J. E. Transparency in Government. In: Word Bank: The Right to Tell. The Role of Mass: Media in Economic. Washington DC: The World Bank, 2002. Disponível em:

$<$ https://www0.gsb.columbia.edu/faculty/jstiglitz/new web/download/pap ers/TransparencyinGovernment-Columbia-(islampaper).pdf.> Acesso em: 11 fev. 2015.

On Liberty, the Right to Know, and Public Discourse: The Role of Transparency in Public Life. Oxford Amnesty Lecture. Oxford, U.K. January 27, 1999. Disponível em:

$<$ https://www0.gsb.columbia.edu/faculty/istiglitz/download/2001 On Libe rty the Right to Know and Public.pdf >. Acesso em: 11 jun. 2015.

TAKAHASHI, T. (Org.). Sociedade da informação no Brasil: livro verde. Brasília: Ministério da Ciência e Tecnologia, 2000. Disponível em:<http://livros01.livrosgratis.com.br/ci000005.pdf > . Acesso em: 19 dez. 2014.

VAZ, J. C.; RIBEIRO, M. M.; MATHEUS, R. Dados governamentais abertos e seus impactos sobre os conceitos e práticas de transparência no Brasil. Cadernos PPG-AU/FAUFBA, v. 9, p. 45-62, 2010. Disponível em: $<$ http://www.portalseer.ufba.br/index.php/ppgau/article/viewFile/5111/3 700>. Acesso em: 10 dez. 2014.

Editor do artigo: Enrique Muriel-Torrado 